\title{
Suicidal attempt by woman in labor
}

\section{Vidyadhar B. Bangal*, Krishna Mandade, Priyanka Verma, Prachi Amrale, Kunal Aher, Dhruval K. Bhavsar}

Department of Obstetrics and Gynecology, Rural Medical College, Pravara Institute of Medical Sciences, Loni, Maharashtra, India

Received: 22 September 2017

Accepted: 27 October 2017

\section{*Correspondence:}

Dr. Vidyadhar B. Bangal,

E-mail: vbb217@rediffmail.com

Copyright: (c) the author(s), publisher and licensee Medip Academy. This is an open-access article distributed under the terms of the Creative Commons Attribution Non-Commercial License, which permits unrestricted non-commercial use, distribution, and reproduction in any medium, provided the original work is properly cited.

\begin{abstract}
Suicidal ideation during delivery is extremely rare. Very few cases have been reported in the literature. Unwanted pregnancies, pre-existent mental disorders, substance abuse or addictions, marital dis-harmony, fetal demise or stillbirths have been documented as associated factors in reported cases of suicidal attempts by women in labour. Women tried taking overdose of sedative pills or have attempted hanging, drowning or jumping from hospital terrace. Lack of prenatal education, suboptimum use of labour analgesia, ill-treatment by health professional and relatives have been the contributory factors for suicidal ideation during pregnancy and labour. We report a rare case of attempted suicide by woman in active labour. She tried to cut the forearm and wrists with the help of razor blade used for preparation of part in preparation room attached to the labour room. The situation was recognized early by vigilant nurse on duty. The woman was resuscitated, treated, and counselled by psychiatrist before discharge from the hospital.
\end{abstract}

Keywords: Care and support in labour, Labour analgesia, Prenatal health education, Suicide during labour

\section{INTRODUCTION}

Labour pains and subsequent parturition are periods of intense stress and fear for many women. The labour experiences remain as lifelong memories. Women with low pain thresh hold often lose their temper and become impatient, aggressive or uncooperative during course of labour. Fear of labour pains often make women choose caesarean section as route of delivery. Unbearable pains and lack of emotional support during the period of labour make women psychotic. Although extremely rare, the literature review on the subject mention about cases of suicidal attempts by women in labour. ${ }^{1}$

Various means were adopted by women to end their life or harm themselves. We report a rare case of attempted suicide by woman in active labour. The situation was recognized early by vigilant nurse on duty. The woman was resuscitated, treated, and counselled by psychiatrist before discharge from the hospital.

\section{CASE REPORT}

Twenty-five years multi-gravida, registered case, labourer by occupation presented to labour room in an emergency with history of seven and half months of amenorrhea, headache and swelling over feet and abdominal pain. She had two living issues from previous pregnancies. Her first baby was born by caesarean section and second by vaginal route without any complication. She had come for three antenatal checkups during present pregnancy and was taking antihypertensive drugs. She was accompanied by her close relatives and husband.

Clinical examination and investigation revealed that she was a case of 30 weeks pregnancy with pre-eclampsia, 
oligo-hydramnios and intrauterine fetal death. Her expected baby weight was 1500 grams. The pelvis and cervix were favourable for induction of labour. She and her husband were explained about the plan of obstetric management. She was induced by sweeping of membranes. She was kept for observation in the labour room. She was allowed to meet her husband in early labour. She went into active labour after 6-8 hours of admission. As woman was unable to tolerate labour pains, she was given labour analgesia. She showed good progress of labour. Her pain thresh hold was low and thus became un-cooperative as labour advanced.

She insisted for caesarean section as she was unable to tolerate the labour pains. She was counselled by the doctor on duty about the good chances of vaginal delivery and no obvious indication for caesarean section in her case. She insisted to meet her husband to discuss about the abdominal route of delivery. She was not staying in bed and repeatedly ran out of labour room. Her husband was asked to talk to her for bearing the pain for few more hours, so that caesarean section could be avoided. Husband explained her about benefits of vaginal delivery as the baby was already dead due to placental insufficiency secondary to hypertension.

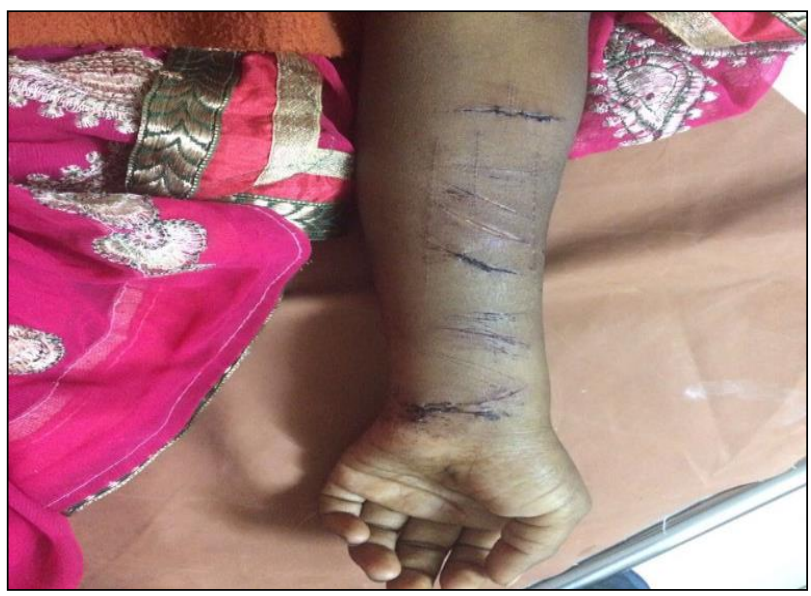

Figure 1: Photograph showing multiple hesitant cuts by blade on left forearm and wrist.

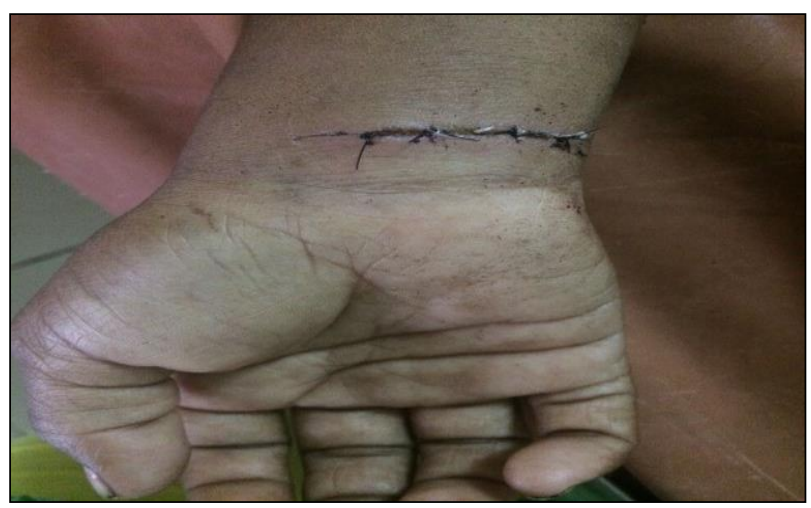

Figure 2: Photograph showing bold cut by blade on right wrist.
After half an hour, patient went to toilet attached to first stage of labour room, after informing the labour room nurse. As she did not return to labour bed after 15 minutes, nurse went near toilet and called her by name. Patient did not respond to call by nurse.

Nurse forcefully opened the toilet door and found that the patient was lying on floor in a pool of blood. Patient was lifted out of the toilet and was examined. She was semiconscious and responding to commands. She was looking pale and had tachycardia and hypotension.

On examination of extremities, it was observed that there were multiple clean-cut wounds on flexor aspects of both wrists and forearms and multiple abrasions due to hesitant cuts by shaving blade, which were actively bleeding. There was a clean incision wound on the scalp which was bleeding. Surgeon was called to take care of cuts on forearms. Patient was resuscitated, and wounds were sutured in labor room. She delivered a dead baby weighing 1500 grams. Patient got access to used razor blade in the preparation room.

Psychiatric consultation was made next day, during which woman confessed that she was upset as the baby was dead and she had unbearable labor pains and she had some arguments with her husband regarding mode of delivery. She was counselled, and anti-psychotic medications were prescribed. She was discharged from hospital after stitch removal. Her husband and other relatives were counselled about taking care of her after going home.

\section{DISCUSSION}

Suicide is a universal public health problem. Asia accounts for $60 \%$ of the world's suicides, so at least 60 million people are affected by suicide or attempted suicide in Asia each year. The suicidal behavior, in terms of total burden of morbidity and mortality combined, is more in women than in men. Women's greater vulnerability to suicidal behavior is likely to be due to gender related causes and to adverse psychosocial factors. ${ }^{1}$

Worldwide reported rate of suicide is around 14/100,000 with $18 / 100,000$ for men and $11 / 100,000$ for women. Suicides represented $1.8 \%$ of the global burden of disease 1998 and is expected to increase to $2.4 \%$ in $2020 .^{2}$ Men and women differ in their roles, responsibilities, status and power and these socially constructed differences interact with biological differences to contribute to differences in their suicidal behavior.

Suicide ranks as the number one cause of mortality in young girls between the ages 15 and 19 years globally. ${ }^{3}$ The menstrual cycle is linked with nonfatal suicidal behavior, with suicide attempts occurring more often in estrogenic phase of the cycle. ${ }^{4}$ This association is marked in women with premenstrual tension. 
Leenaars et al study revealed that $25 \%$ of women who had died by suicide were menstruating at that time compared to $4.5 \%$ of the control group. ${ }^{5}$ Pregnant state is usually considered as having protective effect against suicide, except in teenage mothers, mothers aged $<20$ and in those pregnancies that end in stillbirth or miscarriage, and if the pregnancy is unwanted. ${ }^{6-8}$ In those with postpartum psychosis, suicide risk is increased 7fold in the $1^{\text {st }}$ year after childbirth and 17-fold in the longer term. 6 ,9

For some young women, abortion is a traumatic life event that increases vulnerability to suicidal behavior. Rates of suicidal ideation and mental health problems, including depression, anxiety, and substance use disorders are increased among women who have had induced abortions. $^{7,10,11}$

Women with long duration of infertility have a higher risk of suicide. Pregnancy usually protects against suicide. Suicide rates in pregnancy are estimated to be up to half those of women who are not pregnant. ${ }^{7,10}$ Motherhood, especially when children are very young and most dependent, also protects against suicide. ${ }^{6,7,12}$ Qin et al found that having a child <2-year-old significantly decreased suicide risk for women. ${ }^{13}$

The review of the literature on social support and its relationship to maternal health indicates that emotional support is positively related to mothers' mental and physical health around the time of delivery. During pregnancy, emotional support provided by the husband and other family members is related to the pregnant mother's mental well-being. Information to woman in the form of prenatal classes results in decreased maternal physical complications during labour and delivery, and to better physical and mental health post-delivery.

Mothers who have the support of a companion during labor and delivery experience fewer childbirth complications and less postpartum depression. Mothers' postpartum mental health is related to both the emotional support and practical help (e.g. housework and child care activities) provided by the husband and others. Health care providers are in a unique position to educate prospective parents about the importance of social support around the time of childbirth and may play a critical role in mobilizing support systems for new mothers. $^{14}$

Labor analgesia is often a neglected area in labor management at all types of health care facilities. Many laboring women do not tolerate the labor pains and become restless and uncooperative during labor process. Epidural analgesia is practiced at very few centers. It has few drawbacks and need expertise in putting the epidural catheter. Analgesic drugs like paracetamol have been successfully tried for reducing the severity of labor pains to tolerable level.

\section{CONCLUSION}

Supportive and sympathetic attitude of labour room staff towards women in labour improves the co-operation from labouring women, as well as it reduces the demand for caesarean section for the fear associated to delivery process. The relatives of the labouring woman should understand the level of stress, pain and the fatigue of parturient and should support her psyche and respect her autonomy regarding the mode of delivery. In the present case, the woman tried to harm herself, as she was upset due to intrauterine fetal death and was unable to tolerate the labour pains in spite of administration of parenteral analgesic drugs. The disagreement of woman with husband over mode of delivery and the abusive language used by him further resulted in mental disturbance.

\section{Funding: No funding sources Conflict of interest: None declared Ethical approval: Not required}

\section{REFERENCES}

1. Lakshmi V. Suicide in women. Indian J Psychiatry. 2015;57(2):S233-8.

2. Bertolote JM, Fleischmann A. A global perspective on the magnitude of suicide mortality. In: Wasserman D, Wasserman C, eds. Oxford text book of suicidology and suicide prevention. Oxford, UK: Oxford University Press; 2009:91-8.

3. Ajdacic-Gross V, Weiss MG, Ring M, Hepp U, Bopp M, Gutzwiller F, et al. Methods of suicide: International suicide patterns derived from the WHO mortality database. Bull World Health Organ. 2008;86:726-32.

4. Saunders KE, Hawton K. Suicidal behaviour and the menstrual cycle. Psychol Med. 2006;36:901-12.

5. Leenaars AA, Dogra TD, Girdhar S, Dattagupta S, Leenaars L. Menstruation and suicide: a histopathological study. Crisis. 2009;30:202-7.

6. Appleby L. Suicide during pregnancy and in the first postnatal year. BMJ. 1991;302:137-40.

7. Gissler HE, Lonnqvist J. Suicides after pregnancy in Finland, 1987-1994: Register linkage study. Br Med J Clin Res. 1996;313:1431-4.

8. Vaiva G, Tiessier E, Cottencin O, Goudemand M. On suicide and attempted suicide in pregnancy. Crisis. 1997; 18:20-7.

9. Appleby L, Mortensen PB, Faragher EB. Suicide and other causes of mortality after post-partum psychiatric admission. $\mathrm{Br} \mathrm{J}$ Psychiatry. 1998;173:209-11.

10. Lindahl V, Pearson JL, Colpe L. Prevalence of suicidality during pregnancy and the postpartum. Arch Womens Ment Health. 2005;8:77-87.

11. Fergusson DM, Horwood LJ, Ridder EM. Abortion in young women and subsequent mental health. J Child Psychol Psychiatry. 2006;47:16-24. 
12. Qin P, Mortensen PB. The impact of parental status on the risk of completed suicide. Arch Gen Psychiatry. 2003;60:797-802.

13. Qin $P$, Agerbo E, Westergård-Nielsen N, Eriksson T, Mortensen PB. Gender differences in risk factors for suicide in Denmark. Br J Psychiatry. 2000;177:54650.

14. Gjerdingen DK, Froberg DG, Fontaine P. The effects of social support on women's health during pregnancy, labor and delivery, and the postpartum period. Fam Med. 1991;23(5):370-5.

Cite this article as: Bangal V, Mandade K, Verma $\mathrm{P}$, Amrale P, Aher K, Bhavsar D. Suicidal attempt by woman in labor. Int J Reprod Contracept Obstet Gynecol 2017;6:5650-3. 